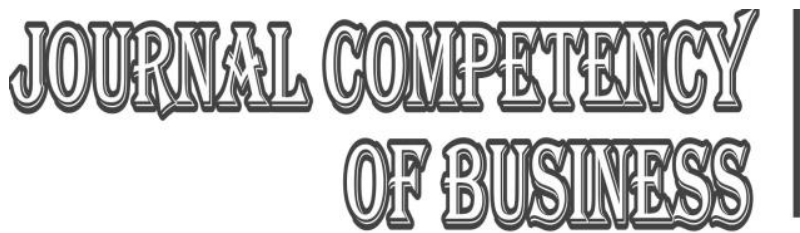

Fakultas Ekonomi, Universitas Cokroaminoto Yogyakarta

Faks : 0274 - 4340644

\title{
PENGARUH PROMOSI DAN KUALITAS LAYANAN TERHADAP KEPUASAN PELANGGAN DI DEALER YAMAHA DETA GROUP CABANG MERDEKA BANDUNG
}

\author{
${ }^{1}$ Rizki Amalia (Universitas Sangga Buana YPKP) \\ ${ }^{1}$ rizkiamalia88888@gmail.com \\ ${ }^{2}$ Ine Aprianti (Universitas Sangga Buana YPKP) \\ ${ }^{2}$ Ine.Aprianti@usbypkp.ac.id
}

\begin{abstract}
ABSTRAK
This study was conducted with the aim of knowing the effect of promotion and service quality that affect customer satisfaction at Yamaha Deta Group Dealers, independent branch. The method used in this research is descriptive verification method with a quantitative approach. This study used 98 respondents as research samples using SPSS 26. The instrument used in this study is a questionnaire with 17 questions consisting of two questions each variable. analysis results obtained from the simple linear regression equation hypothesis testing results showed that the results showed that the variables promotion and the quality of service.
\end{abstract}

\section{Keywords: Promotion, Service Quality And Customer Satisfaction}

\begin{abstract}
ABSTRAK
Penelitian ini dilakukan dengan tujuan untuk mengetahui Pengaruh Promosi dan kualitas layanan yang mempengaruhi kepuasan pelanggan di Dealer Yamaha Deta Group cabang merdeka. Metode yang dilakukan dalam penelitian ini yaitu metode deskriptif verifikatif dengan pendekatan kuantitatif. Penelitian ini menggunakan 98 responden sebagai sampel penelitian dangan menggunakan SPSS26. Instrumen yang digunakan dalam penelitian ini yaitu kuesioner dengan jumlah 17 pertanyaan yang terdiri dari 2 pertanyaan disetiap variabelnya. Berdasarkan hasil pengujian hipotesis diperoleh bahwa hasil penelitian menunjukkan bahwa variabel promosi dan kualitas layanan Secara parsial dan simultan berpengaruh secara signifikan.
\end{abstract}

Kata Kunci: Promosi, Kualitas Layanan Dan Kepuasan Pelanggan 
Fakultas Ekonomi, Universitas Cokroaminoto Yogyakarta

\section{PENDAHULUAN}

Kemajuan teknologi mendorong perkembangan bisnis otomotif yang semakin pesat. Hal ini ditandai dengan banyaknya dealer-dealer sepeda motor baru yang muncul di Indonesia. Adanya impor sepeda motor di Indonesia juga merupakan salah satu bentuk perkembangan bisnis otomotif di Indonesia sehingga menuntut perusahaan untuk melakukan persaingan yang sangat ketat. Usaha menentukan langkah-langkah maju agar sesuai dengan tujuan perusahaan yaitu untuk memperoleh keuntungan semaksimal mungkin dengan potensi dan kemampuan yang maksimal. Ditengah persaingan penjualan sepeda motor yang semakin ketat, perusahaan perlu melakukan perubahan dan perbaikan secara terus menerus untuk meningkatkan penjualan. Salah satu dealer sepeda motor yang telah peneliti lakukan observasi secara langsung yaitu adalah Dealer Yamaha Deta Group cabang Merdeka, Dealer Yamaha Deta Group cabang Merdeka adalah dealer 3S yaitu dealer yang melayani Sales, Service dan Penjualan Sparepart.

Setiap perusahaan pasti mempunyai permasalahan masing masing, selama perusahaan itu masih menjalankan usahanya maka selama itu pula persoalan tersebut masih akan timbul baik itu dari segi layanan, kualitas, fasilitas ataupun kinerjanya. Berdasarkan observasi lapangan, Dealer Yamaha Deta Group cabang Merdeka mengalami masih ada keluhan pelanggan mengenai promosi dan kualitas layanan yang belum sesuai sehingga menimbulkan rasa tidak puas disaat melakukan pembelian.Promosi adalah interaksi antar konsumen maupun calon konsumen untuk 
Fakultas Ekonomi, Universitas Cokroaminoto Yogyakarta seputar produk atau jasa (Gery, 2018:95).

Kualitas layanan yang baik merupakan sesuatu yang diharapkan oleh pelanggan, selain promosi pelanggan akan menilai kualitas layanan apabila sebuah kinerja yang dirasakan sesuai dengan apa yang mereka deskripsikan dalam benak mereka.Keberhasilan konsep pemasaran suatu perusahaan adalah apabila perusahaan tersebut dapat memenuhi kebutuhan pelanggan dengan lebih baik. Selama ini evaluasi promosi dan kualitas layanan yang dimiliki perusahaan untuk membangun kepuasan pelanggan dirasakan masih sangat kurang. Hal itu yang akhirnya juga akan memiliki akibat pelanggan tidak puas.

Kualitas layanan terhadap pelanggan berpengaruh besar terhadap kepuasan pelanggan, yaitu pelayanan yang buruk akan berakibat lebih besar terhadap kepuasan pelanggan daripada pelayanan yang dikategorikan baik, implementasi strategi dengan kategori terbaik akan meningkatkan kepuasan dan kesetiaan pelanggan.

\section{TINJAUANPUSTAKA}

Menurut (Fandy Tjiptono, 2017:3) pemasaran adalah serangkaian aktivitas yang dilakukan untuk menstimulasi permintaan atas produk atau jasa dalam memastikan bahwa produk dijual dan disampaikan kepada para pelanggan.

Menurut (Kotler \& Amstrong dalam Priansa, 2017:3) menjelaskan bahwa pemasaran adalah proses sosial dan manajerial dimana individu dan kelompok 
Fakultas Ekonomi, Universitas Cokroaminoto Yogyakarta bertukar sesuatu yang bernilai dengan pihak lain.

Berdasarkan beberapa definisi di atas yang telah dikemukakan oleh para ahli, bahwa yang dimaksud pemasaran adalah suatu proses untuk mengkomunikasikan atau menyampaikan informasi mengenai produk atau jasa yang dimiliki oleh perusahaan untuk dijual kepada pelanggan

\section{A. Promosi}

Menurut (Handoko, 2017:18) promosi menggambarkan suatu tahap dari hubungan kegiatan pemasaran suatu jasa maupun produk barang. Promosi ialah bagian dari aktivitas kegiatan dan menggambarkan hubungan yang dilakukan perusahaan terhadap pembeli atau konsumen yang mengandung mengambil hati seorang konsumen, pemberitahuan dan mempengaruhi. Semua aktivitas tersebut berfungsi agar menaikkan penjualan, bermutunya suatu barang, bahwa konsumen merasa puas, ini berfungsi untuk mereka, bahwa orang tersebut akan bertransaksi lagi.

Menurut (Ernawati 2019:12) promosi yaitu langkah metode fungsi produk yang menghubungkan dengan pemasaran. Di pasar yang bersaing, kita tidak bisa berharap dari jasa dan barang dijual sendirinya, bukan peduli seberapa banyak kualitas barang, selain konsumen memahami hal tersebut. Promosi memiliki fungsi guna memproleh pelanggan baru, dan menjaga rencana yang ada. 
Fakultas Ekonomi, Universitas Cokroaminoto Yogyakarta

\section{Ada empat indikator promosi (Manap, 2016:304) :}

1. Advertising (periklanan), yaitu semua bentuk presentasi dan promosi nonpersonal yang dibayar oleh sponsor untuk mempresentasikan gagasan, barang atau jasa. Periklanan dianggap sebagai manajemen citra yang bertujuan menciptakan dan memelihara cipta dan makna dalam benak konsumen. Bentuk promosi yang digunakan mencakup broadcast, print, internet, outdoor, dan bentuk lainnya.

2. Sales promotion (promosi penjualan), yaitu insentif-insentif jangka pendek untuk mendorong pembelian atau penjualan suatu produk atau jasa. Bentuk promosi yang digunakan mencakup discounts, coupons, displays, demonstrations, contests, sweepstakes, dan events.

3. Personal selling (penjualan perseorangan), yaitu presentasi personal oleh tenaga penjualan dengan tujuan menghasilkan penjualan dan membangun hubungan dengan konsumen. Bentuk promosi yang digunakan mencakup presentations, trade shows, dan incentive programs.

4. Public relations (hubungan masyarakat), yaitu membangun hubungan yang baik dengan berbagai publik perusahaan supaya memperoleh publisitas yang menguntungkan, membangun citra perusahaan yang bagus, dan menangani atau meluruskan rumor, cerita, serta event yang tidak menguntungkan. Bentuk promosi yang digunakan mencakup press releases, sponsorships, special events, dan web pages. 
Fakultas Ekonomi, Universitas Cokroaminoto Yogyakarta

\section{B. Kualitas Layanan}

Kualitas Layanan adalah upaya pemenuhan kebutuhan dan keinginan pelanggan serta ketepatan penyampaiannya untuk mengimbangi harapan pelanggan (Fandy Tjiptono , 2016:118).

Kualitas pelayanan dipilih untuk kinerja perusahaan melaksanakan kebutuhan dan harapan konsumen yang artinya dalam penelitian ini sinkron dengan keyakinan konsumen, dan maksud lain kualitas pelayanan yaitu aktivitas yang membentuk fungsi dengan menggambarkan peralihan yang diperlukan konsumen agar pelayanan menganjurkan nilai individu bagi konsumen (Aswad, Realize, \& Wangdra, 2018)

\section{Dimensi Kualitas Layanan}

Dimensi kualitas pelayanan yang dikemukakan oleh Fandy tjiptono (2019:305) mengungkapkan ada lima faktor dominan atau penentu kualitas pelayanan yang diantaranya adalah sebagai berikut ini :

1. Bukti fisik (tangible)

Yaitu kemampuan untuk menampilkan yang terbaik bagi pelanggan berupa penampilan fisik, peralatan dan berbagai materi komunikasi yang baik.

2. Empati (empathy)

Yaitu kesediaan karyawan dan pengusaha untuk lebih peduli memberikan perhatian secara pribadi kepada pelanggan. 
Fakultas Ekonomi, Universitas Cokroaminoto Yogyakarta

Faks : 0274 - 4340644

3. Ketanggapan (responsiveness)

Yaitu kemauan karyawan dan pengusaha untuk membantu pelanggan dan memberikan jasa dengan cepat serta mendengar dan mengatasi keluhan pelanggan.

4. Kehandalan (reliability)

Yaitu kemampuan untuk memberikan jasa sesuai dengan harapan konsumen.

5. Kepastian (assurance)

Yaitu berupa kemampuan karyawan untuk menimbulkan keyakinan dan kepercayaan terhadap janji yang telah dikemukakan kepada pelanggan.

\section{Kepuasan Pelanggan}

Kepuasan konsumen dilihat untuk membujuk minat dan perilaku pembelian kembali, dimana pada nantinya akan didapati pendapatan. Kejadian kualitas layanan dan kepuasan konsumen sudah menjadi fokus perhatian disemua industri perbelanjaan. Untuk menarik pelanggan, banyaknya industri yang disuruh untuk mengevaluasi dan menaikkan kualitas layanan untuk konsumen (Anita Mustikasari, 2020:02). Indikator kepuasan pelanggan menurut Fandy Tjiptono (2016:101) yaitu sebagai berikut ini.

1. Kesesuaian harapan, merupakan tingkat kesesuaian antara kinerja produk yang diharapkan oleh pelanggan dengan yang dirasakan oleh pelanggan, meliputi:

a. produk yang diperoleh sesuai atau melebihi dengan yang diharapkan; 
Fakultas Ekonomi, Universitas Cokroaminoto Yogyakarta

b. pelayanan oleh karyawan yang diperoleh sesuai atau melebihi dengan yang diharapkan; dan

c. fasilitas penunjang yang didapat sesuai atau melebihi dengan yang diharapkan.

2. Minat berkunjung kembali, merupakan kesedian pelanggan untuk berkunjung kembali atau melakukan pembelian ulang terhadap produk terkait, meliputi:

a. berminat untuk berkunjung kembali karena pelayanan yang diberikan oleh karyawan memuaskan

b. berminat untuk berkunjung kembali karena nilai dan manfaat yang diperoleh setelah mengkonsumsi produk;

c. berminat untuk berkunjung kembali karena fasilitas penunjang yang disediakan memadai.

3. Kesediaan merekomendasikan, merupakan kesediaan pelanggan untuk merekomendasikan produk yang telah dirasakannya kepada teman atau keluarga, meliputi:

a. menyarankan teman atau kerabat untuk membeli produk yang ditawarkan karena pelayanan yang memuaskan

b. menyarankan teman atau kerabat untuk membeli produk yang ditawarkan karena fasilitas penunjang yang disediakan memadai; 
Fakultas Ekonomi, Universitas Cokroaminoto Yogyakarta

c. menyarankan teman atau kerabat untuk membeli produk yang ditawarkan karena nilai atau manfaat yang didapat setelah mengkonsumsi sebuah produk jasa.

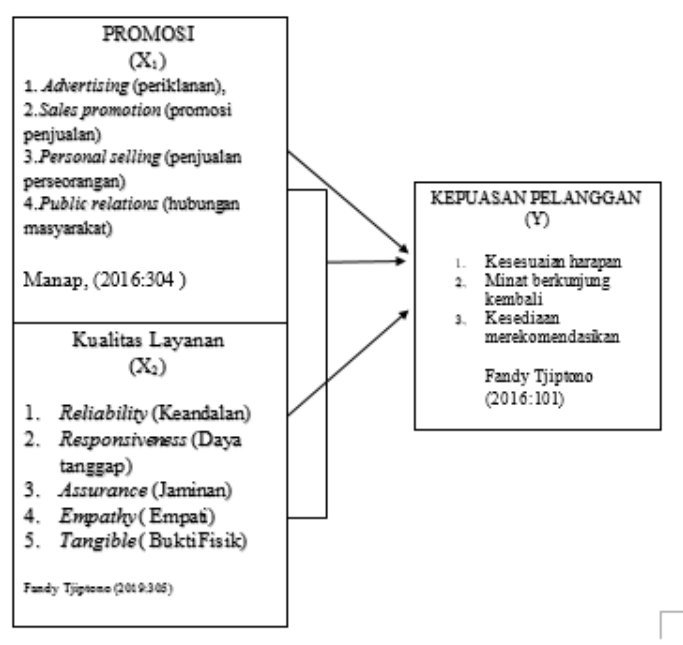

Gambar 1. Paradigma Penelitian

\section{METODEPENELITIAN}

Metode yang digunakan dalam penelitian ini ialah menggunakan analisis deskriptif dan verivikatif, dalam analisis verifikatif data ordinal dalam penelitian ini perlu ditransformasi menjadi data interval menggunakan metode MSI (Method Of Successive Interval) dan dalam penelitian ini yang menjadi obyek penelitian adalah pengaruh promosi dan kualitas layanan di Dealer Yamaha Deta Group Cabang Merdeka. 
Fakultas Ekonomi, Universitas Cokroaminoto Yogyakarta

\section{HASILPENELITIANDANPEMBAHASAN}

\section{Uji F}

Uji simultan atau Uji F ini dilakukan untuk menguji pengaruh dari kedua variabel independen secara bersamaan terhadap variabel dependen. Pada pengujian simultan statistik uji yang digunakan yaitu menggunakan uji $\mathrm{F}$ atau biasa disebut analysis of varian (ANOVA). Berdasarkan hasil pengolahan data yang dilakukan hasil dari Uji F atau Uji Annova sebagai berikut:

Tabel 1.Pengujian Simultan

Tabel Hasil Pengujian Secara Simultan (Uji F)

\begin{tabular}{|l|r|r|r|r|r|r|}
\hline \multicolumn{7}{|c|}{ ANOVA $^{\mathbf{a}}$} \\
\hline \multirow{2}{*}{ Model } & $\begin{array}{c}\text { Sum of } \\
\text { Squares }\end{array}$ & \multicolumn{1}{c|}{ Df } & $\begin{array}{c}\text { Mean } \\
\text { Square }\end{array}$ & \multicolumn{1}{c|}{ F } & Sig. \\
\hline \multirow{2}{*}{1} & Regression & 751.967 & 2 & 375.983 & 138.168 & $.000^{\mathrm{b}}$ \\
\cline { 2 - 7 } & Residual & 258.515 & 95 & 2.721 & & \\
\cline { 2 - 7 } & Total & 1010.472 & 97 & & & \\
\hline
\end{tabular}

a. Dependent Variable: Kepuasan Pelanggan

b. Predictors: (Constant), Kualitas layanan, Promosi

Sumber: Hasil Pengolahan SPSS 26

Dengan nilai $\alpha=5 \% ; \quad \mathrm{df} 1=\mathrm{k}=2 ; \quad \mathrm{df} 2=\mathrm{n}-\mathrm{k}-1=98-2-1=95 \quad$ Berdasarkan hasil perhitungan $F_{\text {hitung }}$ diperoleh sebesar 138,168 dengan nilai $F_{\text {tabel }}$ sebesar 3,09 Karena dari hasil pengujian diperoleh nilai $F_{\text {hitung }}=138,168>F_{\text {tabel }}=3,09$, maka pada $\alpha=$ $5 \%$ dan nilai sig nya $0.000<0.005$ diputuskan untuk menolak $\mathrm{H}_{03}$ sehingga $\mathrm{H}_{\mathrm{a}}$ diterima.

Jadi berdasarkan hasil pengujian dapat disimpulkan bahwa Promosi dan Kualitas Pelayanan berpengaruh secara signifikan terhadap kepuasan pelanggan. 
Fakultas Ekonomi, Universitas Cokroaminoto Yogyakarta

Faks : $0274-4340644$

Tabel 2.Pengujian Parsial

Tabel Hasil Pengujian Secara Parsial (Uji T)

\begin{tabular}{|c|c|c|c|c|c|c|}
\hline \multicolumn{7}{|c|}{ Coefficients $^{\mathrm{a}}$} \\
\hline \multirow{2}{*}{\multicolumn{2}{|c|}{ Model }} & \multicolumn{2}{|c|}{$\begin{array}{l}\text { Unstandardize } \\
\text { d Coefficients }\end{array}$} & \multirow{2}{*}{$\begin{array}{c}\text { Standardized } \\
\text { Coefficients } \\
\text { Beta }\end{array}$} & \multirow[b]{2}{*}{$\mathrm{T}$} & \multirow[b]{2}{*}{ Sig. } \\
\hline & & B & $\begin{array}{l}\text { Std. } \\
\text { Error }\end{array}$ & & & \\
\hline 1 & (Constant) & -.958 & 829 & & -.1156 & .668 \\
\hline & Promosi & .256 & .080 & .307 & 3.202 & .002 \\
\hline & $\begin{array}{l}\text { Kualitas } \\
\text { Layanan }\end{array}$ & .327 & .053 & .553 & 6.139 & .000 \\
\hline
\end{tabular}

a. Dependent Variable: Kepuasan Pelanggan

Hasil pengujian variabel Promosi memperoleh nilai $t_{\text {hitung }}$ sebesar 3,202 dengan tingkat signifikansi sebesar 0,002 dengan menggunakan batas signifikansi < 0,05.Dari hasil tersebut dapat menunjukkan bahwa $t_{\text {hitung }}(3,202)>t_{\text {tabel }}(1,985)$ yang memiliki arti bahwa promosiberpengaruh secara signifikan terhadap Kepuasan Pelanggan.

Uji pengaruh Kualitas Layanan $\left(\mathrm{X}_{2}\right)$ terhadap Kepuasan Pelanggan (Y) Hasil pengujian variabel kualitas memperoleh nilai $t_{\text {hitung }}$ sebesar 6,139 dengan tingkat signifikansi sebesar 0,000, dengan menggunakan batas signifikansi < 0,05.Dari hasil tersebut dapat menunjukkan bahwa $t_{\text {hitung }}(6,139)>t_{\text {tabel }}(1,985)$ yang memiliki arti bahwa kualitas pelayanan berpengaruh secara signifikan terhadap Kepuasan pelanggan. 
Fakultas Ekonomi, Universitas Cokroaminoto Yogyakarta

\section{Analisis Regresi Linier Berganda}

Tabel 3. Regresi Linier Berganda

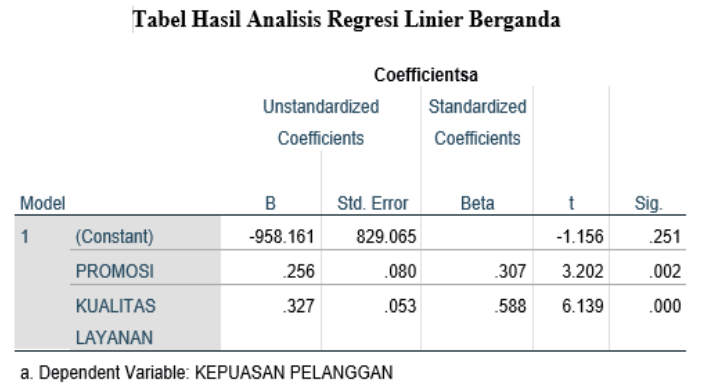

Berdasarkan hasil perhitungan diperoleh bentuk persamaan regresi linier berganda dengan model regresi linier origin atau model regresi tanpa konstanta, sehingga diperoleh persamaan sebagai berikut :

$$
Y=-958.161+256+327+e
$$

Jadi persamaan regresi tersebut dapat dijelaskan sebagai berikut:

a. Konstanta sebesar -958.168 artinya apabila Promosi dan Kualitas Layanan bernilai 0 sementara variabel lain konstan, maka telah terdapat nilai kepuasan pelanggan sebesar -958.168

b. Nilai koefisien regresi variabel Promosi $\left(\mathrm{X}_{1}\right)$ sebesar 0,256 artinya jika variabel independen lain nilainya tetap(konstan) dan Promosi ditingkatkan sebesar satu satuan, maka variabel kepuasan Pelanggan (Y) akan meningkat sebesar 0,256.

c. Nilai koefisien regresi variabel Kualitas Layanan $\left(\mathrm{X}_{2}\right)$ sebesar 0,327 , hal ini dapat diartikan jika variabel independen lainnya memiliki nilai yang tetap (konstan) dan 
Fakultas Ekonomi, Universitas Cokroaminoto Yogyakarta

variabel kualitas pelayanan meningkat sebesar satu satuan, maka Kepuasan Pelanggan (Y) akan meningkat sebesar 0,327.

d. Berdasarkan analisis tersebut, dapat dijelaskan adanya pengaruh atau keeratan hubungan antara variabel independen (Promosi dan kualitas layanan) terhadap variabel dependen (Kepuasan pelanggan)

\section{Uji Koefisien Korelasi}

Tabel 4. Uji Koefisien Korelasi

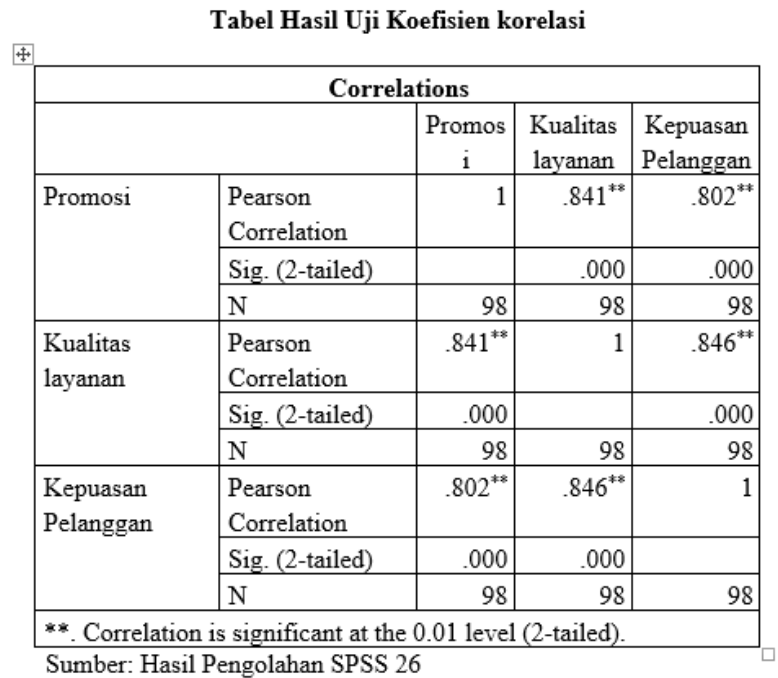

Berdasarkan data di atas korelasi masing-masing variabel independen terhadap variabel dependen adalah:

a. Hubungan antara Promosi $\left(\mathrm{X}_{1}\right)$ dengan Kepuasan Pelanggan $(\mathrm{Y})$ memiliki nilai signifikansi $0,000<0,05$ sehingga berkolerasi dan hubungan antara Promosi dan Kepuasan Pelanggan memiliki nilai adalah 0,802 hubungan ini merupakan 
Fakultas Ekonomi, Universitas Cokroaminoto Yogyakarta

hubungan yang memiliki tingkat hubungan korelasi yang sangat Kuat, karena berada pada interval koefisien0,80 - 1,00berdasarkan pedoman interprets koefisien korelasi. Dengan demikian dapat diinterpretasikan bahwa hubungan antara Promosi terhadap Kepuasan pelanggan memilikitingkat hubungan yang kuat. Tanda positif menunjukkan adanya hubungan linear yang searah antara kedua variabel tersebut.

b. Hubungan antara Kualitas Layanan $\left(\mathrm{X}_{2}\right)$ dengan Kepuasan Pelanggan memiliki nilai signifikansi $0,000<0,05$ sehingga berkolerasi dan hubungan antara kualitas Layanan $\left(\mathrm{X}_{2}\right)$ dengan Kepuasan Pelanggan $(\mathrm{Y})$ memiliki nilai adalah 0,846 hubungan ini merupakan hubungan yang memiliki tingkat hubungan korelasi yang sangat Kuat, karena berada pada interval koefisien0,80 - 1,00berdasarkan pedoman interprets koefisien korelasi. Dengan demikian dapat diinterpretasikan bahwa hubungan antara Kepuasan Pelanggan memilikitingkat hubungan yang kuat. Tanda positif menunjukkan adanya hubungan linear yang searah antara kedua variabel tersebut. 


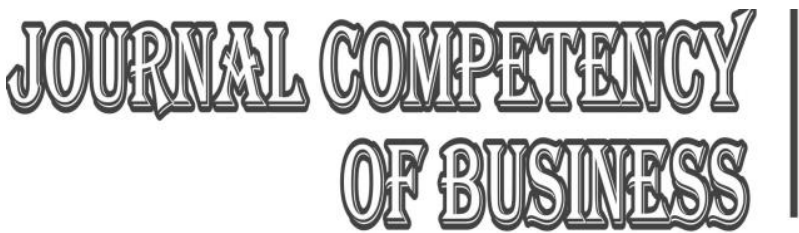

Fakultas Ekonomi, Universitas Cokroaminoto Yogyakarta

\section{Koefisien Determinasi}

Tabel 5. Uji Koefisien Determinasi

Tabel Hasil Uji Koefisien Determinasi

\begin{tabular}{|c|c|c|c|c|}
\hline \multicolumn{5}{|c|}{ Model Summary } \\
\hline Model & $\mathrm{R}$ & R Square & $\begin{array}{l}\text { Adjusted R } \\
\text { Square }\end{array}$ & $\begin{array}{l}\text { Std. Error of } \\
\text { the Estimate }\end{array}$ \\
\hline 1 & $.863^{\mathrm{a}}$ & .744 & .739 & 1.65028 \\
\hline
\end{tabular}

a. Predictors: (Constant), Kualitas layanan, promosi

a. Dependent Variable: Kepuasn Pelanggan

Sumber: Hasil Pengolahan SPSS 26

Hasil analisis data terlihat besarnya angka koefisien determinasi (R Square) yaitu sebesar 0,744 atau sama dengan 74,4 \% Nilai tersebut mengandung arti bahwa variabel Promosi dan kualitas layanan $\left(\mathrm{X}_{2}\right)$ secara simultan (bersama-sama) berpengaruh terhadap variabel Kepuasan (Y) sebesar 74,4\% sedangkan sisanya $(100 \%-74,4 \%=25,6)$ sisanya $25,6 \%$ dipengaruhi oleh variabel lain di luar persamaan regresi ini atau variabel yang tidak diteliti.

\section{KESIMPULAN}

1. Diketahui hasil Diketahui hasil penelitian menunjukkan bahwa variabel promosi (X1) memilikit hitung sebesar 3,202 dan nilai t tabelnya sebesar 1, 985,dari hasil tersebut dapat menunjukkan bahwa $t_{\text {hitung }}(3,202)>t_{\text {tabel }}(1,985)$ yang memiliki arti bahwa promosi berpengaruh secara signifikan terhadap Kepuasan Pelanggan.

2. Diketahui hasil Diketahui hasil penelitian menunjukkan bahwa kualitas layanan (X2) memilikit hitung sebesar 6,139 dengan tingkat signifikansi sebesar 0,000, dengan menggunakan batas signifikansi $<0,05$. Dari hasil tersebut dapat 
Fakultas Ekonomi, Universitas Cokroaminoto Yogyakarta

menunjukkan bahwa $t_{\text {hitung }}(6,139)>t_{\text {tabel }}(1,985)$ yang memiliki arti bahwa kualitas pelayanan berpengaruh secara signifikan terhadap Kepuasan pelanggan.

3. Diketahui hasil penelitian menunjukkan bahwa variabel promosi dan kualitas layanan (X2) memiliki nilai $\mathrm{F}$ hitung sebesar 138,168 dan nilai sig 0.000 dengan nilai F tabel sebesar 3,09. Dengan hasil F hitung $>\mathrm{F}$ tabel dan sig hitung $<0.005$ maka dapat disimpulkan bahwa secara simultan promosi dan kualitas pelayanan berpengaruh terhadap kepuasan pelanggan $(\mathrm{Y})$.

\section{DAFTAR PUSTAKA}

Anita Mustikasari. (2020). Analisis Pengaruh Kualitas Produk Dan Pelayanan Terhadap Tingkat Kepuasan Konsumen (Studi Kasusfood Court Uny). Jurnal DINAMIKA TEKNIK, XIII

Daniel Septian,(2020) Pengaruh promosi dan kualitas layanan terhadap kepuasan Pelanggan di Kepri Mall, Jurnal Manajemen ,44-52

Donni Junni Priansa. (2017). Perilaku Konsumen dalam Bisnis Kontemporer. Bandung: Alfabeta

Ernawati, D. (2019). Pengaruh Kualitas Produk, Inovasi Produk dan Promosi Terhadap Keputusan Pembelian Produk Hi Jack Sandals Bandung. Jurnal Wawasan Manajemen, 7

Fandy, Tjiptono. 2016. Service, Quality \& satisfaction. Yogyakarta. Andi.

. 2016. Pemasaran Jasa (Prinsip, Penerapan, Penelitian). Yogyakarta. Andi.

Gery, M. H. (2018). Pengaruh Kualitas Pelayanan, Lokasi Dan Promosi Terhadap Kepuasan Konsumen the Aliga Hotel Padang. Menara Ilmu, 12(9), 92-102.

Ghozali. (2018). Aplikasi analisis Multivariate dengan program IBM SPSS 25. Semarang: Badan Penerbit Universitas Diponegoro.

Hamdani, N. A., \& Zaman, M. A. (2017). Pengaruh Kualitas Pelayanan dan Promosi terhadap Kepuasan Konsumen pada Pizza Express Jakarta. Jurnal Wacana Ekonomi, 16(2), 037-043. 
Fakultas Ekonomi, Universitas Cokroaminoto Yogyakarta

Faks : 0274 - 4340644

Handoko, B. (2017). Pengaruh Promosi, Harga Dan Kualitas Pelayanan Terhadap Kepuasan Konsumen Pada Titipan Kilat JNE Medan. Jurnal Ilmiah Manajemen \& Bisnis, 18.

Kotler, P., \& Armstrong, G., Priansa, D. (2017). Manajemen Pemasaran. Bandung: CV Pustaka Setia.

Kotler, P., \& Keller, Perjusah,D.(2016). Manajemen Pemasaran edisi 12 Jilid 1 \& 2.Jakarta: PT. Indeks

Leksono dan Herwin. 2017. Pengaruh Harga dan Promosi Grab terhadap Brand Image yang mempengaruhi Keputusan Pembelian, Konsumen Pengguna Transportasi Berbasis Online, Jurnal Riset Manajemen dan Bisnis (JRMB), Vol. 2, No. 3, Pp. 381-390.

Malau, H. (2017). Manajemen Pemasaran teori dan aplikasi pemasaran era tradisional sampai era modernisasi global. Bandung: CV Alfabeta.

Manap. 2016. Revolusi Manajemen Pemasaran. Edisi Pertama, Mitra Wacana Media, Jakarta.

Mardizal, im. (2017). Pengaruh Kualitas Pelayanan, Harga Dan Promosi Terhadap Kepuasan Konsumen Pada Golden Futsal Simpang Haru Padang. Economica, 5(2), 128-133

Uran, S. P. G. O., \& Sugiarso, T. (2017). Pengaruh harga dan kualitas pelayanan terhadap kepuasan konsumen pada CV. Muslim parabola Cileungsi Bogor. Jurnal Administrasi Dan Manajemen, 10.

Priansa, D. (2017). Pemasaran. Bandung: Cv pustaka Setia.

Sugiyono. (2017). Metode Penelitian Kuantitatif, Kualitatif, $R \& D$. Bandung: CV Alfabeta. .(2018). Metode Penelitian Kuantitatif, Bandung: CV Alfabeta. 